\title{
Epidemiology and outcome of cardiac arrest in patients with liver cirrhosis
}

 \\ From ESICM LIVES 2015 \\ Berlin, Germany. 3-7 October 2015
}

\section{Introduction}

Sudden cardiac arrest (CA) is one of the leading causes of death in adults in many parts of the world [1]. Every year estimated 350.000 to 700.000 people in Europe are suffering CA and receive cardiopulmonary resuscitation (CPR) [2]. To date, there is no data available on CA and CPR in patients with liver cirrhosis.

\section{Objectives}

Aim of the study was to determine cause and outcome of CA in patients with liver cirrhosis after CPR.

\section{Methods}

Out of a cohort of 1068 consecutive patients who were successfully resuscitated and treated at the Medical University of Vienna, 47 (4\%) patients with liver cirrhosis could be identified. Patient characteristics, admission diagnosis, severity of disease, course of the disease and $28 \mathrm{~d}$ mortality were assessed.

\section{Results}

Overall 47 patients (35 male, age $60 \pm 11$ years) with liver cirrhosis and CA with successful CPR were assessed. 17 patients had Child-Pugh A, 17 Child-Pugh B and 13 Child-Pugh C. SOFA-Score on admission was $11 \pm 5$, MELD-Score was $18 \pm 8$ on admission. Cause of liver cirrhosis was alcohol in 35 patients, viral hepatitis in 6 patients and other causes in 6 patients.

Cardiac events leading to $C A$ were observed in $21(44 \%)$ patients. Initial rhythm was VF/VT in $10(21 \%)$ patients, asystole in $11(24 \%)$ patients, PEA in $24(51 \%)$ patients and unknown in $2(4 \%)$ patients. 31 (66\%) patients suffered CA out-of-hospital. Time to ROSC was $17 \pm 15$ minutes. 28d-survival was overall 28\%. 37 (78\%) patients were dead after 1 month or had bad neurological outcome (CPC III/IV). None of the patients with Child-Pugh C cirrhosis survived 1 month with good neurologic outcome.

\section{Conclusions}

Cause of CA in patients with liver cirrhosis is rarely cardiac. About one quarter of patients with liver cirrhosis survived more than $28 \mathrm{~d}$ after successful CPR. No patient with Child-Pugh C cirrhosis survived longer than $28 \mathrm{~d}$ after successful CPR with good neurological outcome.

\section{Authors' details}

${ }^{1}$ University Medical Center Hamburg-Eppendorf, Intensive Care Medicine, Hamburg, Germany. ${ }^{2}$ Medical University of Vienna, Department of

Emergency Medicine, Vienna, Austria.

Published: 1 October 2015

\section{References}

1. Sans $\mathrm{S}$, Kesteloot $\mathrm{H}$, Kromhout D: The burden of cardiovascular diseases mortality in Europe. Task Force of the European Society of Cardiology on Cardiovascular Mortality and Morbidity Statistics in Europe. Eur Heart J 1997, 18(8):1231-48.

2. Atwood C, Eisenberg MS, Herlitz J, Rea TD: Incidence of EMS-treated outof-hospital cardiac arrest in Europe. Resuscitation 2005, 67(1):75-80.

\section{doi:10.1186/2197-425X-3-S1-A687}

Cite this article as: Roedl et al:: Epidemiology and outcome of cardiac arrest in patients with liver cirrhosis. Intensive Care Medicine Experimental 2015 3(Suppl 1):A687. 